\title{
Dynamic axial crushing of empty and foam-filled conical aluminium tubes: experimental and numerical analysis
}

\begin{abstract}
This paper presents the crushing behaviour of empty and foam-filled conical tubes under axial dynamic loading. A nonlinear finite element (FE) model was developed and validated against experiments. The validated model was subsequently used to assess the beneficial of foam filling with regards to the variation in filler densities and tube materials. The results obtained were further analyzed and compared with straight tubes. We aim to evaluate the critical effective point for different density of fillers in foam-filled tubes based on specific energy absorption (SEA) value. The SEA value was highest for foam-filled conical aluminium tube with aluminium foam filler, followed by straight aluminium tube, straight carbon steel tube and conical carbon steel tube. Moreover, the initial peak force was found lower in aluminium tubes than carbon steel tubes and lower in conical tubes than that in straight tubes. The combination of conical aluminium tube and aluminium foam filler successfully convey the beneficial of foam filling and thus signify that proper combination and selection of tube and filler is vital in assessing the effectiveness of foam-filled tubes.
\end{abstract}

Keyword: Axial impact; Conical tube; Energy absorption; Finite element; Foam-filled 